\title{
Online Finance And Economics Courses: A Comparative Study Of Course Satisfaction And Outcomes Across Learning Models
}

Linda Wiechowski, Walsh College of Accountancy and Business Administration, USA Terri L. Washburn, Walsh College of Accountancy and Business Administration, USA

\begin{abstract}
Student learning outcomes and course satisfaction scores are two key considerations when assessing the success of any degree program. This empirical study was based upon more than 3,000 end-of-semester course evaluations collected from 171 courses in the 2010-2011 academic year. The study, conducted at a Midwestern business college, considered the model of learning when examining course satisfaction scores of finance and economics courses. The finance and economics courses at the college all use active learning constructs, even in the online and blended course models. Online, blended and face-to-face courses were studied to determine whether there was a statistically significant difference between course satisfaction and any of the models of learning. Surprisingly, online and blended courses had a stronger relationship with high course satisfaction than did face-to-face courses. The average grade point average of each course was also correlated with the three learning models, seeking a relationship between learning outcomes and online, blended and face-to-face courses. There was no significant relationship found among student learning outcomes, as demonstrated by grade point average, and model of learning, indicating that students were able to achieve the same outcomes despite model of learning chosen.
\end{abstract}

Keywords: Online Learning; Active Learning; Student Satisfaction; Learning Outcomes; Finance and Economics Courses

\section{INTRODUCTION}

$\mathrm{n}$ the past decade alone, higher education has seen millions of students depart from the traditional classroom and embrace a fully online model of learning. Online enrollment has grown at a double-digit pace every year while the overall growth in higher education remains below $2 \%$ (Allen \& Seaman,
2010). This clearly shows students are remaining engaged in higher education, but that the enrollment model of preference is shifting from a collocated, face-to-face classroom to one where lecture material, assessments, and interaction is carried out via technology. In line with this growth, finance and economics courses at many institutions of higher education show increasing enrollment numbers in online sections. Yet lacking in the literature is any real focus upon student satisfaction in these two disciplines that are comprised of courses that are challenging even in the face-to-face classroom. This study was undertaken to determine whether the online learning model is an effective way to impart finance and economics skills, particularly when active learning is utilized, and whether this model of learning has any impact upon learning outcomes and student satisfaction.

\section{LITERATURE REVIEW}

\section{Online Course Learning Outcomes}

Allen and Seaman (2011) reported that two-thirds of academic leaders feel that online learning is equal to or superior than face-to-face learning. This is somewhat in conflict with the literature, which appears divided on 
both sides of the efficacy equation. The current literature indicates outcomes are rising in online courses. In his study on student performance and outcomes, Vogel (2011) noted that online students' grades were 16\% higher than that of face-to-face students. A study by the U.S. Department of Education concluded that "students who took all or part of their classes online performed better than those taking the same course through traditional face-to-face instruction" (Agniello, 2010, p. 57). Using a true experimental design, Newlin, Lavooy, and Wang (2007) found that online courses were comparable to the conventional lecture style of face-to-face classes. Rich and Dereshiwsky (2011) ran a comparative analysis among students in online and face-to-face accounting courses and found online students performed as well as those in the face-to-face course. Too, Washburn (2012) correlated a standardized, proctored exit exam with learning model and found that online MBA students outperformed their on-ground peers across five semesters of study. These studies are supportive of the online learning model and its outcomes.

However, dissent exists. Other, mostly earlier studies found online courses to be less effective than face-toface courses (e.g., Anstine \& Skidmore, 2005). An empirical study by Farinelli (2007) indicated that online students scored far below face-to-face students on their final exam; in fact, he noted that "finance is not a fruitful venue for online courses" (p. 45). These earlier studies on the inferiority of online learning (e.g., Moore \& Kearsley, 1996; Moore, 1997; Noble, as cited in Newlin, Lavooy, \& Wang, 2005) seem to be waning, however, and focus is now upon how such constructs as the physical manifestations of communication (Lei \& Govra, 2010), rigidity or flexibility of the course (Zhang, 2003), and social interaction (Muilenburg \& Berge, 2005) impact online student learning outcomes.

In keeping with the current literature, which indicates that the advent of constructivist information processing places the student in the role of information seeker, more institutions of higher education are turning to active learning in the cyber classroom (Shana, 2009; Washburn, 2011). This puts rich media at students' virtual fingertips and allows for a variety of learning modules designed to appeal to multiple learning styles. Written text, voice-over videos and screen-captures, Power Points, simulations, and Flash-based activities all attract the attention of the self-directed learner and offer a variety of opportunities to embrace the content and engage in virtual course room opportunities.

Appealing to differing learning styles is a move deliberately intended to affect student satisfaction and course outcomes. The institution under study for this paper, to be known as "the College," has taken a purposeful and measured approach to designing online courses such that they are equivalent to, or in some cases superior to, their face-to-face counterparts.

\section{Online Course Student Satisfaction}

The typical online learner is a non-traditional student, meaning he is older and more likely to be working (Hunter, 2011; Online Learning, 2010, p. B28). He enters the virtual classroom with "preconceived notions (or lack thereof) of online learning" (Hunter, 2011, p. 75). When unmet, these expectations may lead the student to experience dissatisfaction with the course. Most studies have indicated that satisfaction is linked to instructor involvement and availability; indeed, with "empathy" for the student and "grading leniency," student course satisfaction rises (Hunter, p. 79). Simon, Jackson, and Maxwell (2013) wrote that establishing a learning community (e.g., through instructor involvement) leads to satisfaction, as well. Few studies examined the relationship between course satisfaction and the online learning model without involving the student's perception of the professor.

This current study focuses not primarily upon the instructor, but on course variables such as whether the course was challenging enough, whether the materials were adequate, and whether the technology was appropriate. This study concentrated upon the course itself as opposed to the instructor's involvement or engagement with the course. Thus, it is expected this study will add to the literature for online courses and students' satisfactions levels with the courses themselves.

\section{BACKGROUND OF THE STUDY}

This paper focuses upon the finance (FIN) and economics (ECN) programs at a Midwestern United States business college (the "College"). The FIN and ECN programs fall under the direction of a single department chair 
who oversees all models of these courses thus, the programs are being studied together for this paper. Students are free to take their FIN and ECN classes either fully online, in a blended manner (where approximately half the class sessions meet online and half meet face-to-face in a classroom), or face-to-face (where all class sessions meet in a physical classroom). These three variations are considered the learning model or modality of this study. Students may self-select into the learning model of their choice for each finance or economics course that is part of their degree program.

For many years now, the FIN and ECN department chair has strived to ensure that the content of online courses is as effective and engaging as their face-to-face counterparts. The chair's efforts have been supported by the Division of Online Learning, a team of instructional designers and multimedia specialists employed by the College, whose collective roles are to transform the curricular content into pedagogically-sound online learning modules. This involves rich media and interactive components, in keeping with numerous academic studies which promote short lectures accompanied by engaging activities (e.g., Revere \& Lee, 2011). In fact, active learning and student-centered learning are both key contributors to this study's origin.

For example, in a face-to-face classroom students may be given a problem to work independently, while afterwards watching and listening to the professor as he solves the problem on the whiteboard. Many of the online finance courses at the College use financial calculator simulators, which emulate the classroom experience. The financial calculator simulator captures the voice and calculator movements of the professor as he or she works through finance problems (see Figure 1). This is recorded on the professor's laptop or personal computer, and streamed into a brief video file, which is then placed into the learning management system as part of the course material. The online student accesses the lecture, works the problem, and clicks to observe and listen to the professor provide the solution in the video by demonstrating on the calculator simulator all the steps necessary to do so. Such videos are intentionally loaded with "controls" so that students may stop, rewind, or re-watch the demonstration.

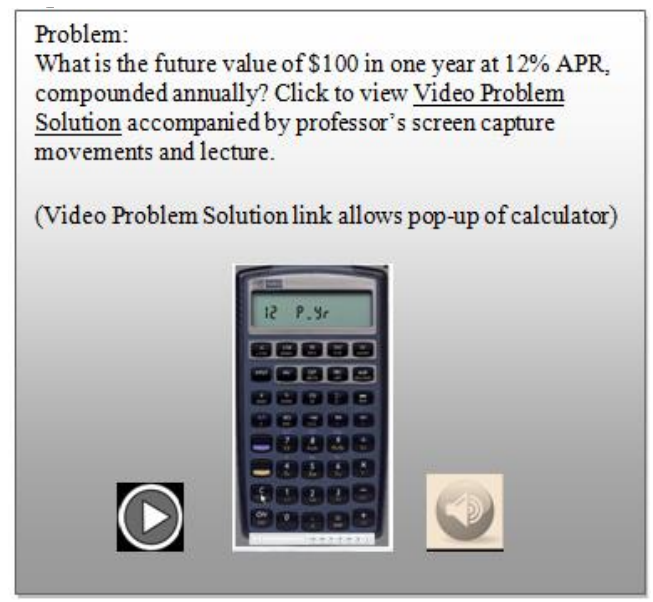

Figure 1: Replication of Financial Calculator Problem and Simulator Solution

Note: There are controls for the student to start, stop and rewind the video.

The same constructs of active learning bear true for economics courses: students are given multiple rich media activities to support the instructor's lecture, and opportunities to reinforce the learning concepts presented to them. In fact, all courses in the FIN and ECN department (as well as the remainder of the College) are expressly designed to mimic or improve upon the classroom experience. Being able to watch the problem being solved over and over again, at a time best suited for the student, may well be seen by the student as an improvement, for example.

The above is but one example of a rich-media example of content in online finance courses at the College. Other examples include Captivate ${ }^{\mathrm{TM}}$ or Camtasia ${ }^{\mathrm{TM}}$ files, which capture mouse and keyboard movements on a PC screen along with the professor's voice, and which are also delivered in a streaming-video format; and simulations wherein students are engaged by asking for input (via mouse-click) to work through decision-making scenarios. 
Several other features are incorporated into many of the online classes to make them interactive. One feature is called a "click-to-reveal" action, where a student is presented with a question within the lecture. After the student has had the opportunity to analyze the question, he then clicks on a link to reveal the solution. The answer to the question appears beneath the question itself, thus becoming part of the lecture content. Too, some of the courses have interactive drag-and-drop exercises or games that enable the student to apply the material they have just learned. In some cases, the students are given the opportunity to work with their classmates on problems via a discussion board, thus enabling peer-to-peer interaction and learning.

\section{STATEMENT OF THE PROBLEM}

Despite supportive studies in the literature, it nonetheless bears consideration whether the addition of rich media and interactive learning has an effect on student satisfaction and outcomes at the College. Therefore, this study will focus upon two disciplines (FIN and ECN) that currently use active learning in all three learning models (online, blended and face-to-face). This study addresses the following research opportunity for the College:

1. Are students who take finance and economics classes at the College equally satisfied with their courses despite model of learning employed in completion of those courses?

2. Are there any differences in course outcomes, as determined by aggregate GPA, despite model of learning employed in completion of those courses?

\section{Research Variables}

Variables for this study include the learning model chosen (independent variable), and course satisfaction and course outcomes (the dependent variables). There was no manipulation of variables in this study, only the intent to measure correlation. The relationship of these variables was studied after the occurrence of the independent variable had already taken place (that is, after students had decided to take their classes online, blended, or face-toface). The above research questions lead to two null hypotheses that form the basis of this study.

\section{Null Hypotheses}

H10: There is no statistically significant difference in the course satisfaction levels of students enrolled in finance and economics courses despite the model of learning utilized by students in these courses.

H2o: There is no statistically significant difference in the course outcomes of students enrolled in finance and economics courses (as determined by aggregate GPA) despite the model of learning utilized by students in these courses.

\section{RESEARCH METHODOLOGY}

Data collected over the course of the 2010-2011 academic year (Fall 2010 to Summer 2011) formed the foundation of this study. Four semesters' worth of student course evaluations and grade distribution reports were gathered and codified in order to best address the hypotheses shown above. The statistical significance level was set at $p<.05$ for the analyses run on each of the hypotheses. After data were scrubbed and codified, the following statistical processing took place:

\section{Statistical Tests upon Course Satisfaction and Learning Model}

The following steps were taken to test for the first hypothesis:

1. Descriptive statistics were run on the variables comprising aggregate (or overall) course satisfaction.

2. Descriptive statistics were run on the aggregate variable of course satisfaction.

3. A Shapiro-Wilk Test of Normality was run on the aggregate course satisfaction variable.

4. The non-parametric test, Kruskal-Wallis, was executed on the aggregate variable of course satisfaction.

5. A Tukeys HSD Post-Hoc test was used to analyze between-groups significance of the learning model. 


\section{Statistical Tests upon Average Course GPA and Learning Model}

The following steps were taken to test for the second hypothesis:

1. Descriptive statistics were run on the aggregate variable of average GPA.

2. A Shapiro-Wilk Test of Normality was run on the aggregate course satisfaction variable.

3. A One-Way Analysis of Variance (ANOVA) was run to determine significance between average GPA and learning model.

4. A Games-Wallis Post-Hoc test used to analyze between-groups significance of the learning model.

\section{The Population}

During the 2010-2011 academic year, 171 finance and economics courses were taught at the College, comprising a total enrollment of 4,163 students. The data consists of 68 online courses, 26 blended courses, and 77 face-to-face courses. Approximately $60 \%$ of the courses were graduate courses and $40 \%$ were undergraduate courses. Course evaluations were offered to all students; thus, this was a census survey for the population chosen for the study. Overall, of the 4,163 course evaluation instruments distributed, $73 \%$ of students responded, resulting in over 3,000 completed course evaluations. The tests for this research study were run on average course scores (satisfaction) and average GPA (outcomes) and not on individual students' scores.

\section{The Research Instrument for Student Course Satisfaction}

Students were given a course survey during the last few weeks of each semester. The course evaluation instrument contained nearly two dozen 5-point Likert scale questions. However, only five of those questions made up the course satisfaction score; the remaining sought input on the instructor. For this study, the researchers chose to focus upon course satisfaction, not instructor satisfaction. A 5-point Likert scale format is used to assess the student's satisfaction for each of the questions (agree, somewhat agree, neither agree nor disagree, somewhat disagree, disagree). The results of the five questions are combined to calculate an overall student satisfaction score for each course, representing the dependent variable in this study.

Table 1: Individual Variables Comprising Course Satisfaction Score

\begin{tabular}{|l|l|}
\hline \multicolumn{1}{|c|}{ Variable } & \multicolumn{1}{c|}{ Survey Question } \\
\hline Expectations & The course expectations and requirements were sufficiently challenging. \\
\hline Materials & The course materials, including textbooks, handouts and assignments were appropriate and helpful. \\
\hline Syllabus & $\begin{array}{l}\text { The course schedule, guidelines, objectives and grade determination were included in the syllabus and } \\
\text { followed throughout the semester. }\end{array}$ \\
\hline Objectives & $\begin{array}{l}\text { The course schedule, guidelines, objectives and grade determination were included in the syllabus and } \\
\text { followed throughout the semester. }\end{array}$ \\
\hline Technology & $\begin{array}{l}\text { The instructor demonstrated proficiency with online course facilitation OR technology, if any, was } \\
\text { appropriate, easy to use, and effective in helping me learn. }\end{array}$ \\
\hline
\end{tabular}

\section{Research Instrument for Student Grade Variable}

An average grade point average (GPA) by course was calculated from the grade distribution report for each course. This average GPA is used for the reported analysis in this paper. Two other grade variables from the student survey were analyzed as well. One survey question asked the student was: "The grade I think I earned in this course is" and the other question was: "The grade I am likely to receive is." Surprisingly, the results of the analysis did not change with the use of the students' perceptions of their expected grade, so the average GPA from the grade distribution reports were used for the following analysis.

\section{DATA ANALYSIS}

\section{Student Course Satisfaction}

The researchers first tested for the first hypothesis, which read: There is no statistically significant difference in the course satisfaction levels of students enrolled in finance and economics courses despite the model 
of learning utilized by students in these courses. Though the course evaluation instrument contained nearly two dozen 5-point Likert scale questions, only five of those questions made up the course satisfaction score. A Cronbach's Alpha test for reliability was run on the questions. A Cronbach's Alpha is a statistical test used when there are numerous Likert-scale questions in an instrument, and the researcher wishes to determine the likelihood that the scale is reliable. Typically a researcher looks for a reliability coefficient of .70 or higher. The Cronbach's Alpha score of .807 is an indication that the questions all measure the same latent variable of course satisfaction. The results of the Cronbach's Alpha test can be seen in Table 2.

Table 2: Cronbach's Alpha for Reliability on Course Satisfaction

\begin{tabular}{|c|c|c|}
\hline Cronbach's Alpha & Cronbach's Alpha Based on Standardized Items & n \\
\hline .807 & .857 & 5 \\
\hline
\end{tabular}

The following table shows the descriptive statistics for each of the five individual questions in the student course satisfaction score.

Table 3: Descriptive Statistics on Individual Course Satisfaction Variables

\begin{tabular}{|l|c|c|c|c|}
\hline \multicolumn{1}{|c|}{ Variable } & Mean & Minimum & Maximum & Std. Deviation \\
\hline Expectations & 4.6376 & 3.72 & 5.00 & .29744 \\
\hline Materials & 4.3495 & 3.00 & 5.00 & .44216 \\
\hline Syllabus & 4.6323 & 2.11 & 5.00 & .42201 \\
\hline Objectives & 4.4927 & 2.67 & 5.00 & .45707 \\
\hline Technology & 4.2388 & 1.28 & 5.00 & .77847 \\
\hline
\end{tabular}

The course satisfaction score for each course is an average of the five individual questions. The average of all course satisfaction courses was 4.47 , with blended courses earning the highest average of 4.63 and face-to-face courses earning the lowest average course satisfaction score of 4.28. A breakdown of the course satisfaction scores can be seen in Table 4.

Table 4: Descriptive Statistics for Aggregate Course Satisfaction Scores

\begin{tabular}{|l|c|c|c|c|c|}
\hline \multicolumn{1}{|c|}{ Learning Model } & $\mathbf{N}$ & Mean & Minimum & Maximum & Std. Deviation \\
\hline Online & 68 & 4.6286 & 3.37 & 4.95 & .28552 \\
\hline Blended & 26 & 4.6332 & 3.55 & 5.00 & .33810 \\
\hline F2F & 77 & 4.2752 & 3.26 & 4.89 & .37819 \\
\hline Total & 171 & 4.4702 & 3.26 & 5.00 & .37976 \\
\hline
\end{tabular}

The above table indicates that students in face-to-face courses are not as satisfied with their courses as are students in online or blended courses. To evaluate the variance between the course satisfaction scores of the different learning models deployed, the researchers evaluated the normality of the data using the Shapiro-Wilk test. The $p$-values for the Shapiro-Wilk tests were all less than .05, indicating that the course satisfaction score is not normally distributed for any of the learning models, as shown in Table 5.

Table 5: Shapiro-Wilk Test of Normality for Course Satisfaction

\begin{tabular}{|l|c|c|c|}
\hline \multicolumn{1}{|c|}{ Learning Type } & Statistic & Sig \\
\hline Online & .846 & 68 & .000 \\
\hline Blended & .822 & 26 & .000 \\
\hline F2F & .947 & 77 & .003 \\
\hline
\end{tabular}

Because the data were not normally distributed, a non-parametric test was appropriate. The Kruskal-Wallis test is a non-parametric test that was used to test the null hypothesis "There is no statistically significant difference in the course satisfaction levels of students enrolled in finance and economics courses despite the model of learning utilized by students in these courses." The resulting significance value of $p=.000$ was found, resulting in a rejection of the null hypothesis. This result indicates that there is a statistically significant difference in the course satisfaction found between the three learning models. See Table 6. 
Table 6: Kruskal-Wallis Test Summary for Course Satisfaction

\begin{tabular}{|l|c|c|c|}
\hline \multicolumn{1}{|c|}{ Null Hypothesis } & Test & Sig. & Decision \\
\hline $\begin{array}{l}\text { The distribution of Course Satisfaction is the same across } \\
\text { categories of Learning Model. }\end{array}$ & $\begin{array}{c}\text { Independent-Samples } \\
\text { Kruskal-Wallis Test }\end{array}$ & .000 & Reject the null hypothesis \\
\hline
\end{tabular}

The significance level is .05 .

When studying between-groups correlations, post-hoc tests help determine differences between sub-groups of the population; here, among the sub-groups of the learning model (i.e., online, blended, face-to-face). To determine where the course satisfaction means differ among the learning models, a post hoc test was performed. Equal variances were first found using the Levene's Test of Homogeneity of Variance, indicating the appropriate post hoc test was the Tukey HSD Post Hoc test. See Table 7 for the Levene's test:

Table 7: Test of Levene's Homogeneity of Variances for Course Satisfaction

\begin{tabular}{|c|c|c|c|}
\hline Levene Statistic & df1 & df2 & Sig. \\
\hline 2.911 & 2 & 168 & .057 \\
\hline
\end{tabular}

As noted, the level of significance was set at $p<.05$. The Tukey HSD Post Hoc test indicated that there are significance differences between the course satisfaction of online courses and face-to-face courses $(p=.000)$, as well as between blended courses and face-to-face courses $(p=.000)$. Interestingly, there was found to be no significant difference in the course satisfaction between online and blended courses $(p=.998)$. The results can be seen in Table 8 , below.

Table 8: Tukeys HSD Post Hoc Test

\begin{tabular}{|c|c|c|c|c|c|c|}
\hline \multicolumn{7}{|c|}{\begin{tabular}{|l|} 
Dependent Variable: CourseSatis \\
\end{tabular}} \\
\hline \multirow{2}{*}{ (I) LearningType } & \multirow{2}{*}{ (J) LearningType } & \multirow{2}{*}{ Mean Difference (I-J) } & \multirow{2}{*}{$\begin{array}{c}\text { Std. } \\
\text { Error }\end{array}$} & \multirow{2}{*}{ Sig. } & \multicolumn{2}{|c|}{ 95\% Confidence Interval } \\
\hline & & & & & Lower Bound & Upper Bound \\
\hline \multirow{2}{*}{ Online } & Blended & -.00459 & .07793 & .998 & -.1889 & .1797 \\
\hline & F2F & $.35346^{*}$ & .05624 & .000 & .2205 & .4865 \\
\hline \multirow{2}{*}{ Blended } & Online & .00459 & .07793 & .998 & -.1797 & .1889 \\
\hline & F2F & $.35806^{*}$ & .07666 & .000 & .1768 & .5393 \\
\hline \multirow{2}{*}{$\mathrm{F} 2 \mathrm{~F}$} & Online & $-.35346^{*}$ & .05624 & .000 & -.4865 & -.2205 \\
\hline & Blended & $-.35806^{*}$ & .07666 & .000 & -.5393 & -.1768 \\
\hline
\end{tabular}

* The mean difference is significant at the 0.05 level.

\section{Student Grades}

The average GPA for each course was calculated from grade distribution reports generated from the end-ofsemester grade reporting system. As shown in Table 9, the blended courses had the highest average grades while the online courses had the lowest average grades. The blended courses had the greatest variance, having both the lowest average GPA of 2.19 as well as the highest average GPA of 3.83 .

Table 9: Descriptive Statistics: Student GPAs

\begin{tabular}{|l|c|c|c|c|c|}
\hline \multicolumn{1}{|c|}{ Learning Model } & $\mathbf{N}$ & Mean & Minimum & Maximum & Std. Deviation \\
\hline Online & 68 & 2.9940 & 2.28 & 3.78 & .33958 \\
\hline Blended & 26 & 3.1078 & 2.19 & 3.83 & .43942 \\
\hline F2F & 77 & 3.0971 & 2.34 & 3.60 & .25274 \\
\hline Total & 171 & 3.0577 & 2.19 & 3.83 & .32421 \\
\hline
\end{tabular}

To evaluate the variance between the GPAs of the different learning models employed, the normality of the data was evaluated using a Shapiro-Wilk test. The $p$-values for the Shapiro-Wilk tests were all greater than .05, indicating that the course satisfaction score is normally distributed for each of the learning models, as shown in Table 10 . 
Table 10: Shapiro-Wilk Test of Normality for GPA

\begin{tabular}{|l|c|c|c|}
\hline \multicolumn{1}{|c|}{ Learning Type } & Statistic & df & Sig \\
\hline Online & .966 & 68 & .062 \\
\hline Blended & .967 & 26 & .540 \\
\hline F2F & .975 & 77 & .136 \\
\hline
\end{tabular}

A one-way ANOVA was run to test for the second hypothesis, which read: There is no statistically significant difference in the course outcomes of students enrolled in finance and economics courses (as determined by aggregate GPA) despite the model of learning utilized by students in these courses. The resulting significance value of $p=.111$ was returned, resulting in the acceptance of the null hypothesis. This indicates that there is not a statistically significant difference in the average GPA found between the three learning models, as shown in Table 11 for the ANOVA results.

Table 11: One Way ANOVA: Average GPA and Learning Model

\begin{tabular}{|l|c|c|c|c|c|}
\hline ANOVA & \multicolumn{3}{l|}{. } \\
\hline AvgGPA & Sum of Squares & df & Mean Square & F & Sig. \\
\hline & .461 & 2 & .231 & 2.225 & .111 \\
\hline Between Groups & 17.408 & 168 & .104 & & \\
\hline Within Groups & 17.869 & 170 & & & \\
\hline Total & & & & \\
\hline
\end{tabular}

Although the ANOVA test indicated there is no statistically significant difference in the average GPAs between the different learning models, a post hoc test was performed in an attempt to confirm the results. Since equal variances were not found using the Levene's test (Table 12, $p=.001$ ), it was determined that the appropriate post hoc test was the Games-Howell Post Hoc test.

Table 12: Test of Levene's Homogeneity of Variances for Average GPAs

\begin{tabular}{|l|c|c|c|}
\hline Levene Statistic & df1 & df2 & Sig. \\
\hline 7.215 & 2 & 168 & .001 \\
\hline
\end{tabular}

As can be seen in Table 13, the average GPAs are not statistically different between the learning models $(p=.001)$. This indicated that the independent variable of learning model did not have a significant relationship with the average GPA for each course.

Table 13: Games-Howell Post-Hoc to Determine Between-Groups Relationship

\begin{tabular}{|c|c|c|c|c|c|c|}
\hline \multicolumn{7}{|c|}{ Multiple Comparisons } \\
\hline \multicolumn{7}{|c|}{ Dependent Variable: AvgGPA } \\
\hline \multicolumn{7}{|c|}{ Games-Howell } \\
\hline \multirow{2}{*}{ (I) LearningType } & \multirow{2}{*}{ (J) LearningType } & \multirow{2}{*}{ Mean Difference (I-J) } & \multirow{2}{*}{ Std. Error } & \multirow{2}{*}{ Sig. } & \multicolumn{2}{|c|}{ 95\% Confidence Interval } \\
\hline & & & & & Lower Bound & Upper Bound \\
\hline \multirow{2}{*}{ Online } & Blended & -.11381 & .09551 & .466 & -.3470 & .1194 \\
\hline & $\mathrm{F} 2 \mathrm{~F}$ & -.10316 & .05025 & .104 & -.2224 & .0161 \\
\hline \multirow{2}{*}{ Blended } & Online & .11381 & .09551 & .466 & -.1194 & .3470 \\
\hline & F2F & .01065 & .09086 & .992 & -.2131 & .2344 \\
\hline \multirow{2}{*}{$\mathrm{F} 2 \mathrm{~F}$} & Online & .10316 & .05025 & .104 & -.0161 & .2224 \\
\hline & Blended & -.01065 & .09086 & .992 & -.2344 & .2131 \\
\hline
\end{tabular}

\section{DISCUSSION OF THE FINDINGS}

This empirical study was carried out to determine whether there was a statistically significant difference in student course satisfaction scores and student learning outcomes across three different learning models: face-to-face, blended, and online. Finance and economics courses offered at a Midwestern business college were used for this study. The study consisted of data from 171 courses and over 3,000 student evaluations collected from the Fall 2010 through Summer 2011 semesters. 


\section{Course Satisfaction}

After performing descriptive statistics and tests for reliability and normality of the data, a Kruskal-Wallis test was performed on learning model and aggregate course satisfaction score. The significance level was set to .05, and the $p$-value returned was .000; thus, the researchers rejected the null hypothesis and determined that there did indeed exist a statistically significant relationship between model of learning and course satisfaction. Students taking online and blended courses were more satisfied with their courses than were those who opted for the face-toface learning model. A Tukeys Honest Significant Differences post hoc tested between-groups scores, and found that online and blended courses had the strongest relationship with higher course satisfaction.

Though this finding bodes well for the online or blended learning model, the same cannot quite be said for the face-to-face model, whose average course satisfaction level (4.27 out of 5.0) was significantly lesser than the online (4.62) and blended (4.63) course satisfaction scores. Though the students' feelings about the instructor did not figure into the aggregate course satisfaction score, it cannot be discounted that those feelings may have influenced the score. However, in general, it is the same instructors who teach all models of each course in the FIN and ECN curriculum: online, blended and face-to-face. Too, even though the convenience of blended and online learning was not part of the satisfaction score, it also cannot be discounted that convenience did not weigh into the students' overall feelings about satisfaction, even though they were not specifically asked about course convenience.

It is therefore possible that the convenience and availability of the online and blended learning models factored into the course satisfaction, if for no other reason than that students were able to visit the course material multiple times. The ability to view and review the material is an advantage not granted the face-to-face student, who experiences each weekly class only one time.

\section{Course Outcomes}

It was found in this study that the model of learning does not correlate significantly with average GPAs. Although the average GPA was lowest for online courses and highest for blended courses, the differences were not statistically significant; thus, the researchers accepted the null hypothesis: there was not a statistically significant relationship between GPA (or learning outcomes) and learning model. This can be interpreted in a positive way: it can be stated that learning outcomes for finance and economics courses at the College have no significant relationship with learning model; that is, online and blended students are able to achieve the same outcomes as their face-to-face counterparts, and vice versa. This is of critical importance when considering that student learning outcomes should be the same despite model of learning.

\section{Summary of Findings}

Overall, blended courses had the highest average GPAs and the highest course satisfaction scores, while the lowest course satisfaction score was found in face-to-face courses and the lowest average GPA, although not statistically significant, was found in online courses. The results noted above indicate that although the grades were slightly lower in the online courses, students were more satisfied with the online and blended courses than the faceto-face courses.

\section{LIMITATIONS OF THE STUDY}

There exist several limitations to this study. First, students were able to self-select into the learning model they desired. A true experimental design would have placed students into the different models in a random manner, limiting the amount of personal preference they had for each learning style. Secondly, the students in this study were all non-traditional students; that is, they were older and in general had more business experience than traditional students.

The study was carried out at a single institution and therefore cannot be generalized to the higher education population in general. The College under study has invested considerable resources in online and blended course design, which may not be representative of other institutions; thus, it cannot be said that all online and blended 
courses at all institutions would result in the same findings. The study did not differentiate between online nonactive learning courses. Including online and blended courses that did not demonstrate the active learning construct may have resulted in less correlation between satisfaction and learning model. In other words, students may not have been as satisfied if the online and blended courses were not as inclusive of rich media. Therefore, this study is more demonstrative of the nature of online and blended learning courses that employ active learning than those online and blended learning courses that contained more static learning material.

\section{RECOMMENDATIONS FOR FUTURE RESEARCH}

Both online and blended courses need to be analyzed further to determine the most successful aspects of the courses in terms of course satisfaction and student learning outcomes. Blended courses were found to have both the highest student satisfaction score as well as the highest average GPAs, suggesting further research could be very beneficial. At the College there are new variations of the blended model being offered, and each needs to be evaluated. While some instructors may choose to meet in class and online each week in a blended course, others may vary their delivery between online and face-to-face on a weekly basis. Too, qualitative analyses may be of interest. The course evaluation instrument is limiting in nature, not allowing the researchers to explore nuances of each question. A mixed methods study may also be beneficial, building upon the quantitative nature of the survey by following up with explorative questions in a qualitative manner.

Courses that are not based upon active learning, the constructivist model, and rich media should be examined as well. It may be that satisfaction was largely dependent upon these factors. Finally, future studies should include other academic disciplines and venture outside finance and economics courses.

\section{AUTHOR INFORMATION}

Dr. Linda Wiechowski is the Chair of the Economics and Finance Department at Walsh College of Accountancy and Business Administration, a private non-profit business college located in Troy, Michigan. Dr. Wiechowski specializes in teaching financial management and economics in the MBA program as well as finance in the BBA and MSF programs. She has also taught health economics, health care finance, as well as a variety of computer courses. Dr. Wiechowski has developed and taught numerous online courses. She has also presented "Online Best Practices" at a variety of educational conferences. E-mail: 1wiechow@walshcollege.edu (Corresponding author)

Dr. Terri Washburn is the Assistant Vice President and Dean of Academic Technology for Walsh College of Accountancy and Business Administration, a private non-profit business college located in Troy, Michigan. She is the former Dean of the Division of Online Learning at the same institution. Her $\mathrm{PhD}$ is in Management, and her dissertation sought a correlational analysis between learning model and leadership style. She teaches graduate and undergraduate courses in management and information technology. E-mail: twashburn@walshcollege.edu

\section{REFERENCES}

1. Allen, I. E., \& Seaman, J. (2011). Going the distance: Online education in the United States. Needham, MA: The Sloan Consortium. Retrieved February 25, 2012 from http://www.onlinelearningsurvey.com/reports/goingthedistance.pdf

2. Allen, E., \& Seaman, J. (2010). Class differences: Online education in the United States, 2010. Needham, MA: The Sloan Consortium. Retrieved January 2, 2013, from http://sloanconsortium.org/publications/survey/pdf/class_differences.pdf

3. Anstine, J., \& Skidmore, M. (2005). A small sample study of traditional and online courses with sample selection adjustment. Journal of Economic Education, 36(2). 107-127.

4. Farinella, J. (2007). Professor and student performance in online versus traditional introductory finance courses. Journal of Economics and Finance Education, 6(1), 40-47.

5. Hunter, D. Y. (2011). Who holds the pen? Strategies to student satisfaction scores in online learning environments. The Business Review, Cambridge,18(2), 75-81.

6. Lei, S. A., \& Govra, R. K. (2010). College distance education courses: Evaluating benefits and costs from institutional, faculty and students' perspectives. Education, 130(4), 616-631. 
7. Moore, M. (1997). Theory of transactional distance. In D. Keegan (Ed.), Theoretical principles of distance education (pp.22-38). New York: Routledge.

8. Moore, M., \& Kearsley, G. (1996). Distance education: A systems review. Belmont, KY: Wadsworth Publishing Company.

9. Muilenburg, L. Y., \& Berge, Z. L. (2005). Student barriers to online learning: A factor analytic study. Distance Education, 26(1), 29-48.

10. Newlin, M. H., Lavooy, M. J., \& Wang, A. Y. (2005). An experimental comparison of conventional and web-based instructional formats. North American Journal of Psychology, 7(2), 327-335. Retrieved from http://search.proquest.com/docview/198088566?accountid=27965

11. Revere, L., \& Kovach, J. (2011). Online technologies for engaged learning. A meaningful synthesis for educators. Quarterly Review of Distance Education, 12(2), 113-120.

12. Rich, A. J., \& Dereshiwsky, J. I. (2011). Assessing the comparative effectiveness of teaching undergraduate intermediate accounting in the online classroom format. Journal of College Teaching and Learning, 8(9), 19-27.

13. Shana, Z. (2009). Learning with technology: Using discussion forums to augment a traditional-style class. Educational Technology \& Society, 12(3), 214-228.

14. Washburn, T. L. (2011). Leading into the future: An exploration of learning modality and leadership style. Capella University. ProQuest Dissertations and Theses, Retrieved from http://search.proquest.com/docview/916606516? accountid=27965

15. Washburn, T. L. (December, 2012). A correlational analysis of outcomes across learning models: Why students outperform in online classes. The Exchange, A Journal of the Academic Forum.

16. Zhang, L. (2003). Contributions of thinking styles to critical thinking dispositions. Journal of Psychology, 137(6), 517-543. doi:10.1080/00223980309600633 
NOTES 